\title{
Dysmetabolic Iron Overload and Cardiometabolic Diseases. Cause-Effect Relationship or Indirect Association?
}

\author{
M Pilar Vaquero ${ }^{1 *}$ and Francisco J Sánchez Muniz ${ }^{2}$ \\ ${ }^{1}$ Department of Metabolism and Nutrition, Spanish National Research Council (ICTAN-CSIC), Spain \\ ${ }^{2}$ Departmet of Nutrition and Food Science, Universidad Complutense, Spain
}

Submission: June 28, 2018; Published: July 18, 2018

*Corresponding author: M Pilar Vaquero, Department of Metabolism and Nutrition, Institute of Food Science, Technology and Nutrition, Spanish National Research Council (ICTAN-CSIC), José Antonio Novais 10. 28040-Madrid, Spain, Email: mpvaquero@ictan.csic.es

\begin{abstract}
The prevalence of cardiometabolic diseases is increasing all over the world. Insulin resistance has been proposed as one major factor of the Metabolic syndrome (MetS) that ultimately leads to type 2 Diabetes Mellitus (T2DM). The relationship between iron status and MetS has been scarcely described. This mini-review presents on one hand the existing knowledge on the effects of excess body iron (iron overload) on insulin resistance and on the other the link between hyperglycemia and alterations in iron metabolism. When the binding capacity of serum transferrin exceeds normal levels, free-iron induces the formation of reactive oxygen species (ROS) which may increase oxidative stress and cause tissue damage. In addition, ROS have been linked to insulin resistance, reduction in adiponectin release, and non-alcoholic fatty liver, among others. It is also discussed that as a consequence of glucose excess, transferrin, as other proteins, becomes glycated decreasing its iron binding capacity resulting in elevated free-iron levels and the consequent deleterious effects. As in both, T2DM and hemochromatosis patients, a significant high ferritin-dyslipemia relationship has been reported, present review hypothesizes that iron stored as "ferritin" partially escapes to plasma contributing to the vicious circle. Increases in liver free fatty acids availability and gluconeogenesis aggravate insulin resistance, giving rise to adyslipemic profile. Nonetheless, several points and action mechanisms are still poorly understood and require more studies to elucidate the role of iron in the etiology of cardiometabolic diseases. Finally, it is suggested that subjects predisposed to cardiometabolic diseases and/or to accumulate iron should limit the prolonged consumption of iron supplements or iron fortified foods. Strategies to decrease the bioavailability of iron in such vulnerable population groups, such as recommending high vegetable diets, deserve future investigation.
\end{abstract}

Keywords: Cardiovascular diseases; Ferritin; Hepcidin; Insulin resistance; Iron overload; Metabolic syndrome; ROS; Transferrin; Type 2 diabetes mellitus

Abbreviations: HDL: High Density Lipoproteins; HDL-cholesterol: Cholesterol Carried by High Density Lipoproteins; LDL: Low Density Lipoproteins; MetS: Metabolic Syndrome; NASH: Non-Alcoholic Steatohepatitis; ROS: Reactive Oxygen Species; T2DM: Type 2 Diabetes Mellitus

\section{Introduction}

Iron is a micronutrient involved in many organic functions. It is essential for the oxygen transport and participates in numerous enzymatic systems related to cellular respiration, synthesis of DNA, RNA and proteins, as well as others involved in antioxidant defense and immunity. However, since iron is both an electron donor and acceptor, it has the potential to generate free radicals [1,2]. Iron status is regulated at the level of absorption, and numerous ingested food components can enhance or inhibit its bioavailability [3] (Figure 1, number 1). Iron deficiency anemia affects health and life quality and may produce growth retardation and decreases in physical and intellectual performance with the subsequent public health and socioeconomic impacts [3]. Homeorretic mechanisms exist to adapt the body to the iron deficiency. When body iron should be increased, hepcidin -a hormone that blocks iron transport from the intestine and storage cells (eg. hepatocytes and macrophages) to the blood- is downregulated in order to increase net absorption and maintain functional iron [2,3]. In this condition, iron supplementation and the consumption of iron-fortified foods can effectively restore this metal status [3-7].

At the other extreme, excess of iron may be more harmful to the body than iron deficiency. Thus, patients with primary hemochromatosis or hemochromatosis secondary to massive transfusions develop diabetes and abdominal obesity [8-10]. In these patients, phlebotomies and iron chelators improve blood glucose and insulin sensitivity $[11,12]$ but the mechanism by 


\section{Current Research in Diabetes \& Obesity Journal}

which this improvement occurs has not yet been well elucidated. The initial physiologic adaptation to high iron intakes is to store this metal in the enterocyte of the intestinal barrier in the form of ferritin; thus, the non-absorbed iron can be eliminated by desquamation of the intestinal mucosa that is renovated every three to four days [13] (Figure 1, number 2). This mechanism is highly dependent on hepcidin function at the basolateral membrane. However, once iron is absorbed, iron excess is not efficiently regulated by excretion mechanisms, as serum transferrin becomes saturated and the excess occurs as nontransferrin bound iron (NTBI) that may induce the formation of reactive oxygen species (ROS) and result toxic (Figure 1, number 3) [13]. Thus, tissue iron overload is a major threat and can cause metabolic alterations that lead to cardiovascular disease, diabetes, hepatic damage, and kidney disease [2].

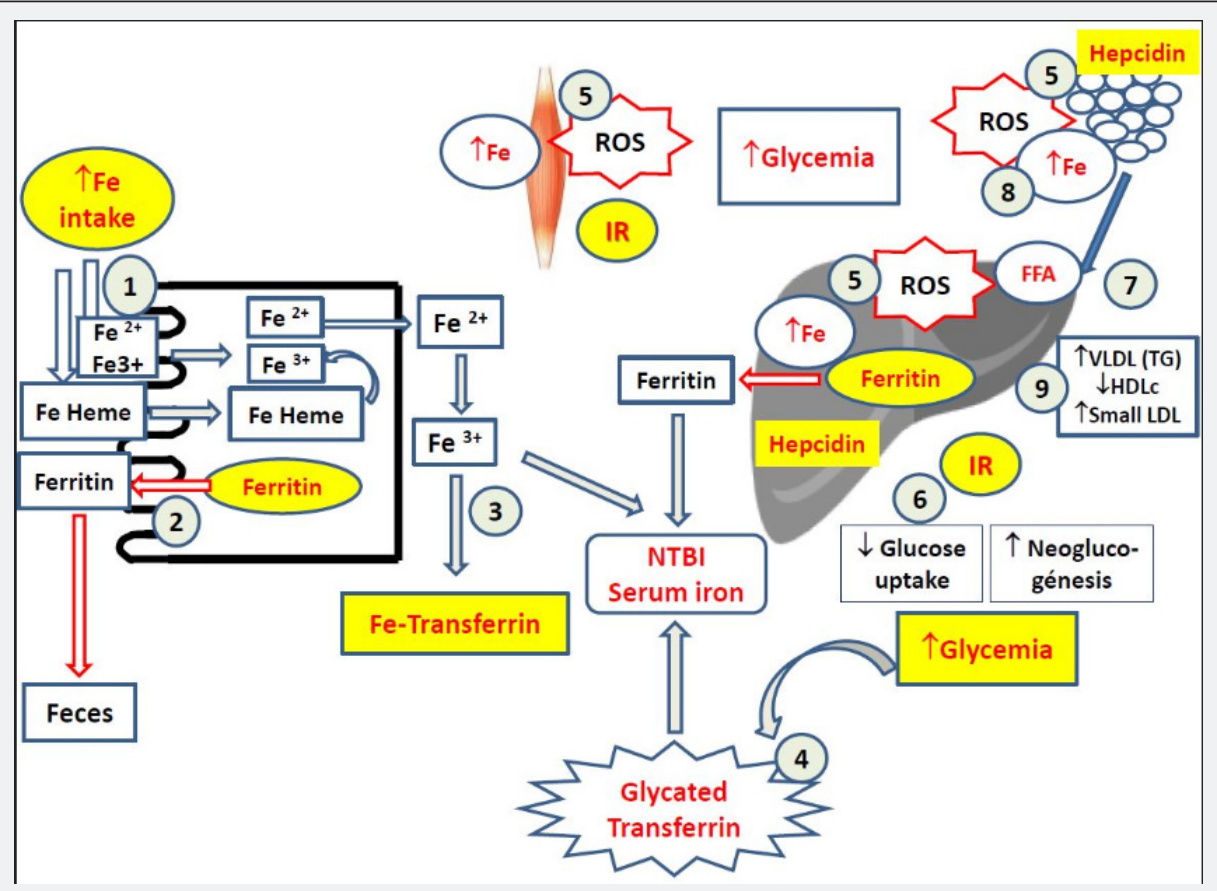

Figure 1: Hypothesis linking insulin resistance with iron overload.

1. Iron status is regulated at the level of absorption. Numerous ingested food components can enhance (e.g. vitamin C) or inhibit (e.g. tannins) its bioavailability.

2. The non-absorbed iron can be eliminated by desquamation of the intestinal mucosa.

3. Iron excess is not efficiently regulated by excretion mechanisms, as serum transferrin becomes saturated and the excess occurs as nontransferrin bound iron (NTBI).

4. Transferrin glycation decreases its ability to bind ferric iron, and consequently increases the free-iron pool and enhances oxidative damage.

5. Iron contributes to form reactive oxygen species (ROS) in tissues and may result toxic.

6. Insulin resistance limits cellular glucose uptake and induces liver neoglucogenesis contributing to hyperglucemia.

7. Iron excess increases the presence of free fatty acids, major gluconeogenesis substrates contributing to increase even more the liver insulin resistance and the hyperglycemia.

8. Adipocyte iron overload. Visceral and subcutaneous fats locally increased hepcidin expression.

IR: Insulin Resistance, FFA: Free Fatty Acids; ROS: Reactive Oxygen Species

Hyperglycemia, high glycated hemoglobin and advance glycation products are consistent features in non-controlled diabetes and appear involved in the pathology of T2DM and insulin resistance [14,15]. Regarding the iron connection, it is known that transferrin glycation decreases its ability to bind ferrous iron, and consequently increases the free-iron pool and enhances oxidative damage [16] (Figure 1, number 4). Oxidative stress itself induces insulin resistance, which contributes to maintain a vicious circle [17]. Significantly higher liver iron concentrations, determined by magnetic resonance, have been observed in prediabetic $(100-126 \mathrm{mg} / \mathrm{dL}$ glucose) compared to control subjects (40.6 vs $27.8 \mu \mathrm{mol} / \mathrm{g}$, respectively) [18]. Similarly, increases in iron storage, determined by serum ferritin, have been shown in other prediabetic situations $[19,20]$, in the Metabolic syndrome (MetS) [21-23], and in non-alcoholic steatohepatitis (NASH) that frequently is observed in the MetS [24]. Once again this relationship has been confirmed in a recent meta-analysis [25]. In addition, the probability to be diagnosed of prediabetes in individuals classified in the 4th quartile for ferritin values vs those of the 1st quartile was 2.08 times higher (95\% CI 1.43-3.04) [26]. Similar results were previously observed by the National Health and Nutrition Examination Survey (NHANES) 1999-2002 [27]. Iron action mechanisms intervening in cardiometabolic diseases are not completely understood. The most accepted hypothesis is the one that relates the pro-oxidant character of iron with ROS production (Figure 1, number 5), 


\section{Current Research in Diabetes \& Obesity Journal}

that increases the oxidative stress in several organs as the liver and arterial wall, as reviewed previously [2]. The ROS increase would also affect $\beta$-pancreatic cell reducing insulin synthesis and secretion [28]. Another potential mechanism may involve a decrease in insulin sensitivity of peripheral tissues, situation that limits cellular glucose uptake, leading to preference for fatty acid oxidation [29] (Figure 1, number 6). Consequently, iron excess increases the presence of free fatty acids, major gluconeogenesis substrates contributing to increase even more the liver insulin resistance and the hyperglycemia (Figure 1, number 7) [29].

Adiponectin has been recognized to increase insulin cell sensitivity [30]. Interestingly, iron excess reduces adiponectin expression, contributing to decrease its synthesis by adipocytes. In this regard, knockout mice which did not express ferroportin (an exporter protein) in their adipocytes (Fpn1 -/-) and showed adipocyte iron overload, presented decreased adiponectin synthesis and marked insulin resistance [30]. In addition, visceral and subcutaneous fats of obese patients locally increased hepcidin expression and reduced transferrin receptor expression, suggesting altogether an adipocyte iron overload in obese patients (Figure 1, number 8). The increment in hepcidin expression in the adipose tissue of these patients inversely correlates with the adiponectin expression and directly with the insulin resistance [31]. These results agree with previous studies in which adipose tissue and muscle contain higher iron concentration measured by magnetic resonance analyses in obese than in non-obese patients $[32,33]$. In mouse models it has been found that hepcidin is induced by gluconeogenic signals [34,35]. It appears therefore that hepcidin expression tends to preserve tissue iron for vital activities during starvation. However, Vecchi et al. [35] suggested that if the condition of gluconeogenesis persists, excess iron may be harmful. Other authors suggest that the double insulin resistance-hepcidin resistance may explain the involvement of iron in diabetes, obesity, and fatty liver disease [2].

Finally, dyslipemia has been considered a central factor of cardiometabolic diseases. Regarding the connection between low body iron and lipids, it is known that anemia leads to low levels of circulating triglycerides and total cholesterol, which recover with the reversal of anemia [36]. Yet, the iron hypothesis published by Sullivan in Lancet in the 80's of the previous century relates the lower incidence of cardiometabolic disease in women with their lower body iron content [37]. In contrast, we have found in diabetics a correspondence between serum ferritin, marker of body iron, and various lipid alterations [2]. Moreover, several studies and a meta-analysis consistently show that T2DM patients present moderate to high levels of serum ferritin [38-41]. Our results from 595 diabetics belonging to the DICARIVA study clearly show that patients included in the highest quartile for ferritin showed higher triglyceridemia and lower cholesterol carried by High Density Lipoproteins (HDL-cholesterol) than those at the lowest ferritin quartile [2]. Differences were higher in men than in women suggesting some gender effect and additional link with the iron hypothesis previously commented [37]. Furthermore, diabetics belonging to the 4th quartile of ferritin show higher triglycerides/HDL molar ratio, suggesting the presence of smaller and more atherogenic Low Density Lipoproteins (LDL), vs those of the 1st quartile of ferritin (Figure 1, number 9). Time ago we found a significant relationship between iron levels in umbilical cord blood and HDL-cholesterol [42], suggesting the demand of this particle to reduce peroxidation risk at birth. On the other hand, some studies and meta-analysis have demonstrated a relationship between dietary iron intake, particularly heme iron or red meat and T2DM development [43-45]. Interestingly, the increased consumption of iron supplement during pregnancy has been related to gestational diabetes [46-48]. This observation may have important repercussions due to the general recommendation of increasing iron intake during pregnancy to prevent anemia [49]. It should be taken into account that iron absorption is enhanced in pregnancy and that there are no iron losses due to menstruation. Therefore, the implication of excess iron supplementation on gestational diabetes has nutritional, etiologic, metabolic, clinic and therapeutic importance and deserves special attention.

With this scientific background, phlebotomies have been used trying to treat diabetes and prediabetes. In a study conducted in patients with nonalcoholic steatohepatitis, phlebotomies decreased insulin concentration, insulin resistance and improved lipid levels [50], but no positive effects were observed in another randomized study [51]. Results from a randomized study conducted in a group of 64 MetS patients showed that those subjected to phlebotomies showed a significant decrease in blood pressure, glycaemia, glycosylated hemoglobin and cardiovascular risk index [52]. It is a widely accepted fact that iron depletion by phlebotomies prevents the onset of T2DM in patients with hereditary hemochromatosis. In addition, insulin resistance has been shown to decrease among blood donors [6]. Finally, a subsequent study conducted in 28 high ferritin diabetic men randomized 13 of them to perform 3 phlebotomies. At 4 months, a decrease in the glycated hemoglobin (HBA1c) levels, in the secretion of insulin and an increase in insulin sensitivity was observed in the phlebotomized group $[53,54]$. Taking into account all commented studies, it seems clear that iron status is clearly related with the cardiometabolic disease. However, at present we are not ready to answer the question of whether the relationship is direct or indirect as several factors act simultaneously. Nonetheless, some studies highlight the idea that reducing iron levels (e.g. decreasing iron absorption) could improve insulin resistance and prevent deleterious effects on the oxidative status mediated by iron overload. Although some cardiometabolic pathologies are associated to oxidative stress and chronic inflammation, new reports indicate that iron may also play direct actions in a number of metabolic routes. In this regard, the convenience to use high protein diets which are rich in iron in the treatment/prevention of obesity and/or MetS seems at least reviewable. In addition, we think that the excessive 
intake of products that increase iron bioavailability might be controlled (e.g. vitamin C, heme iron, iron fortified food) in the frame of a high iron content diet. As we exactly do not know if such iron excess induces insulin resistance and hyperglycemia or if the hyperglycemia followed by hyperinsulinemia and insulin resistance is caused by transferrin glycation, we recommend decreasing the hemo availability in people affected by MetS non-affected of anemia through increasing the daily intake of vegetables. Thus, eating more vegetables would permit to a) decrease the intake of foods with high iron content; b) increase the intake of low iron bioavailability food; c) increase consumption of phenolic compounds and antioxidant vitamins that would contribute to decrease the prooxidant status of T2DM or MetS patients.

\section{Acknowledgement}

Study partially granted by project AGL 2014-53207-C2-2R.

\section{Conflict of Interest}

Authors declare that no conflicts of interest exist.

\section{References}

1. Toxqui L, De Piero A, Courtois V, Bastida S, Sanchez-Muniz FJ, et al. (2010) Iron deficiency and overload. Implications in oxidative stress and cardiovascular health. Nutr Hosp 25(3): 350-365.

2. Vaquero MP, García-Quismondo A, del Cañizo FJ, Sánchez-Muniz FJ (2017) Iron status biomarkers and cardiovascular risk. In: Kumar A (Ed.), Intech, Recent trends in cardiovascular risks. Rijeka, Croatia, Balkans, pp. 98-117.

3. Blanco-Rojo R, Vaquero MP (2018) Iron bioavailability from food fortification to precision nutrition. A review. Inn Food Sci \& Emerging Technol.

4. Blanco-Rojo R, Perez-Granados AM, Toxqui L, Gonzalez Vizcayno C, Delgado MA, et al. (2011) Efficacy of a microencapsulated iron pyrophosphate-fortified fruit juice: a randomised, double-blind, placebo-controlled study in Spanish iron-deficient women. Br J Nutr 105(11): 1652-1659.

5. Navas-Carretero S, Perez-Granados AM, Sarria B, Vaquero MP (2009) Iron absorption from meat pate fortified with ferric pyrophosphate in iron-deficient women. Nutrition 25(1): 20-24.

6. Navas-Carretero S, Perez-Granados AM, Schoppen S, Sarria B, Carbaja A, et al. (2009) Iron status biomarkers in iron deficient women consuming oily fish versus red meat diet. J Physiol Biochem 65(2): 165-174.

7. Wright I, Blanco-Rojo R, Fernández MC, Toxqui L, Moreno G, et al. (2013) Bone remodelling is reduced by recovery from iron-deficiency anaemia in premenopausal women. J Physiol Biochem 69(4): 889-896.

8. Hatunic M, Finucane FM, Brennan AM, Norris S, Pacini G, et al. (2010) Effect of iron overload on glucose metabolism in patients with hereditary hemochromatosis. Metabolism 59(3): 380-384.

9. De Sanctis V, Soliman A, Yassin M (2013) Iron overload and glucose metabolism in subjects with $\beta$-thalassaemia major: an overview. Curr Diabetes Rev 9(4): 332-341.

10. Freixenet $N$, Remacha $A$, Berlanga E, Caixàs $A$, Giménez-Palop 0 , et al. (2009) Serum soluble transferrin receptor concentrations are increased in central obesity. Results from a screening programme for hereditary hemochromatosis in men with hyperferritinemia. Clin Chim Acta 400(1-2): 111-116.
11. Hatunic M, Finucane FM, Norris S, Pacini G, Nolan JJ (2010) Glucose metabolism after normalization of markers of iron overload by venesection in subjects with hereditary hemochromatosis. Metabolism 59(12): 1811-1815.

12. Casanova-Esteban P, Guiral N, Andrés E, Gonzalvo C, Mateo-Gallego R, et al. (2011) Effect of phlebotomy on lipid metabolism in subjects with hereditary hemochromatosis. Metabolism 60(6): 830-834.

13. Williams JM, Duckworth CA, Burkitt MD, Watson AJM, Campbell BJ, et al. (2015) Epithelial cell shedding and barrier function: A matter of life and death at the small intestinal villus tip. Vet Pathol 52(3): 445-455.

14. Rybinska I, Cairo G (2017) Mutual cross talk between iron homeostasis and erythropoiesis. Vitam Horm 105: 143-160.

15. Nowotny K, Jung T, Höhn A, Weber D, Grune T (2015) Advanced glycation end products and oxidative stress in type 2 diabetes mellitus. Biomolecules 5(1): 194-222.

16. Fernandez-Real JM, Ricart W, Arroyo E, Balança R, Casamitjana R, et al. (1998) Serum ferritin as a component of the insulin resistance syndrome. Diabetes Care 21(1): 62-68.

17. Udipi S, Ghugre P, Gokhale Ch (2012) Iron, oxidative stress and health. Oxidative Stress, Volodymyr Lushchak, Intech Open, pp. 73-108.

18. Zheng X, Jiang T, Wu H, Zhu D, Wang L, et al. (2011) Hepatic iron stores are increased as assessed by magnetic resonance imaging in a Chinese population with altered glucose homeostasis. Am J Clin Nutr 94(4): 1012-1019.

19. Sharifi F, Nasab NM, Zadeh HJ (2008) Elevated serum ferritin concentrations in prediabetic subjects. Diab Vasc Dis Res 5(1): 15-18.

20. Mascitelli L, Pezzetta F (2006) High iron stores and impaired endotelial function in prediabetic subjects. Am J Cardiol 97(10): 1550.

21. Moirand R, Mortaji A, Lore'al O, Paillard F, Brissot P, et al. (1997) A new syndrome of liver iron overload with normal transferrin saturation. Lancet 349(9045): 95-97.

22. Sun L, Franco OH, Hu FB, Cai L, Yu Z, et al. (2008) Ferritin concentrations, metabolic síndrome, and type 2 diabetes in middle-aged and elderly chinese. J Clin Endocrinol Metab 93(12): 4690-4696.

23. Vari IS, Balkau B, Kettaneh A, Andre P, Tichet J, et al. (2007) Ferritin and transferrin are associated with metabolic syndrome abnormalities and their change over time in a general population: Data from an Epidemiologic study on the insulin resistance síndrome (DESIR). Diabetes Care 30(7): 1795-1801.

24. Dongiovanni P, Fracanzani AL, Fargion S, Valenti L (2011) Iron in fatty liver and in the metabolic síndrome: a promising therapeutic target. J Hepatol 55(4): 920-932.

25. Jin Y, He L, Chen Y, Fang Y, Yao Y (2015) Association between serum ferritin levels and metabolic syndrome: an updated meta-analysis. Int J Clin Exp Med 8(8): 13317-13322.

26. Huth C, Beuerle S, Zierer A, Heier M, Herder C, et al. (2015) Biomarkers of iron metabolism are independently associated with impaired glucose metabolism and type 2 diabetes: the KORA F4 study. Eur J Endocrinol 173(5): 643-653.

27. Cheung CL, Cheung TT, Lam KS, Cheung BM (2013) High ferritin and low transferrin saturation are associated with pre-diabetes among a national representative sample of U.S. adults. Clin Nutr 32(6): 10551060.

28. Fernandez-Real JM, McClain D, Manco M (2015) Mechanisms linking glucose homeostasis and iron metabolism toward the onset and progression of Type 2 Diabetes. Diabetes Care 38(11): 2169-2176.

29. Huang Jones D, Luo B, Sanderson M, Soto J, Abel ED, et al. (2011) Iron overload and diabetes risk: a shift from glucose to Fatty Acid 


\section{Current Research in Diabetes \& Obesity Journal}

oxidation and increased hepatic glucose production in a mouse model of hereditary hemochromatosis. Diabetes 60(1): 80-87.

30. Gabrielsen JS, Gao Y, Simcox JA, Huang J, Thorup D, et al. (2012) Adipocyte iron regulates adiponectin and insulin sensitivity. J Clin Invest 122(10): 3529-3540.

31. Pihan Le Bars F, Bonnet F, Loréal O, Le Loupp AG, Ropert M, et al. (2016) Indicators of iron status are correlated with adiponectin expression in adipose tissue of patients with morbid obesity. Diabetes Metab 42(2) 105-111.

32. Fernández-Real JM, Blasco G, Puig J, Moreno M, Xifra G, et al. (2016) Adipose tissue R2* signal is increased in subjects with obesity: A preliminary MRI study. Obesity 24(2): 352-358.

33. Moreno-Navarrete JM, Blasco G, Xifra G, Karczewska Kupczewska M, Stefanowicz M, et al. (2016) Obesity is associated with gene expression and imaging markers of iron accumulation in skeletal muscle. J Clin Endocrinol Metab 101(3): 1282-1289.

34. Wang H, Li H, Jiang X, Shi W, Shen Z, et al. (2014) Hepcidin is directly regulated by insulin and plays an important role in iron overload in streptozotocin-induced diabetic rats. Diabetes 63(5): 1506-1518.

35. Vecchi C, Montosi G, Garuti C, Corradini E, Sabelli M, et al. (2014) Gluconeogenic signals regulate iron homeostasis via hepcidin in mice. Gastroenterology 146(4): 1060-1069.

36. Remacha AF, Wright I, Fernández-Jiménez MC, Toxqui L, Blanco-Rojo R et al. (2015) Vitamin B12 and folate levels increase during treatment of iron deficiency anaemia in young adult woman. Int J Lab Hemato 37(5): 641-648

37. Sullivan JL (1981) Iron and the sex difference in heart disease risk Lancet 1(8233): 1293-1294.

38. Swaminathan S, Fonseca VA, Alam MG, Shah SV (2007) The role of iron in diabetes and its complications. Diabetes Care 30(7): 1926-1933.

39. Simcox JA, McClain DA (2013) Iron and diabetes risk. Cell Metab 17(3): 329-341.

40. Luan de C, Li H, Li SJ, Zhao Z, Li X, et al. (2008) Body iron stores and dietary iron intake in relation to diabetes in adults in North China Diabetes Care 31(2): 285-286.

41. Kunutsor SK, Apekey TA, Walley J, Kain K (2013) Ferritin levels and risk of type 2 diabetes mellitus: An updated systematic review and meta-analysis of prospective evidence. Diabetes Metab Res Rev 29(4): 308-318.

42. Bastida S, Vaquero MP, Veldhuizen M, Sánchez-Muniz FJ (2000) Selected trace elements and minerals in cord blood: association with lipids and lipoproteins at birth. Acta Paediatr 89(10): 1201-1206.
43. Bao W, Rong Y, Rong S, Liu L (2012) Dietary iron intake, body iron stores, and the risk of type 2 diabetes: A systematic review and metaanalysis. BMC Medicine 10: 119.

44. Zhao Z, Li S, Liu G, Yan F, Ma X, et al. (2012) Body iron stores and hemeiron intake in relation to risk of type 2 diabetes: a systematic review and meta-analysis. PLoS One 7(7): e41641.

45. Pan A, Sun Q, Bernstein AM, Manson JE, Willett WC, et al. (2013) Changes in red meat consumption and subsequent risk of type 2 diabetes mellitus: three cohorts of US men and women. JAMA Intern Med 173(14): 1328-1335

46. Fu S, Li F, Zhou J, Liu Z (2016) The relationship between body Iron status, iron intake and gestational diabetes: A systematic review and meta-analysis. Medicine 95(2): e2383.

47. Helin A, Kinnunen TI, Raitanen J, Ahonen S, Virtanen SM, et al. (2012) Iron intake haemoglobin and risk of gestational diabetes: A prospective cohort study. BMJ Open 2(5).

48. Qiu C, Zhang C, Gelaye B, Enquobahrie DA, Frederick IO, et al. (2011) Gestational diabetes mellitus in relation to maternal dietary heme iron and non heme iron intake. Diabetes Care 34(7): 1564-1569.

49. Sánchez-Muniz FJ, Gesterio E, Espárrago Rodilla M, Rodríguez Bernal B, Bastida S (2013) La alimentación de la madre durante el embarazo condiciona el desarrollo pancreático, el estatus hormonal del feto y la concentración de biomarcadores al nacimiento de Diabetes mellitus y síndrome metabólico. Nutr Hosp 28(2): 250-274.

50. Facchini FS, Hua NW, Stoohs RA (2002) Effect of iron depletion in carbohydrate-intolerant patients with clinical evidence of nonalcoholic fatty liver disease. Gastroenterology 122(4): 931-939.

51. Adams LA, Crawford DH, Stuart K, House MJ, St Pierre TG, et al. (2015) The impact of phlebotomy in nonalcoholic fatty liver disease: a prospective, randomized, controlled trial. Hepatology 61(5): 15551564.

52. Houschyar KS, Lüdtke R, Dobos GJ, Kalus U, Broecker Preuss M, et al (2012) Effects of phlebotomy-induced reduction of body iron stores on metabolic syndrome: results from a randomized clinical trial. BMC Med 30: 10-54

53. Fernández-Real JM, López-Bermejo A, Ricart W (2005) Iron stores, blood donation, and insulin sensitivity and secretion. Clin Chem 51(7): 1201-1205.

54. Fernandez-Real JM, Peñarroja G, Castro A, García-Bragado F, LópezBermejo A, et al. (2002) Blood letting in high-ferritin type 2 diabetes Effects on insulin sensitivity and beta-cell function. Diabetes 51(4): 1000-1004.

\section{Your next submission with Juniper Publishers will reach you the below assets}

- Quality Editorial service

- Swift Peer Review

- Reprints availability

- E-prints Service

- Manuscript Podcast for convenient understanding

- Global attainment for your research

- Manuscript accessibility in different formats

( Pdf, E-pub, Full Text, Audio)

- Unceasing customer service

Track the below URL for one-step submission https://juniperpublishers.com/online-submission.php 